\title{
NISTIR 4927
}

\section{Limited Tests to Investigate Whether the Size of Body Armor Samples Influences Ballistic Test Results}

\section{Keith R. Eberhardt}

Computing and Applied Mathematics Laboratory Statistical Engineering Division

\section{Lawrence K. Eliason}

Electronics and Electrical Engineering Laboratory Office of Law Enforcement Standards

U.S. DEPARTMENT OF COMMERCE Technology Administration National Institute of Standards and Technology

Gaithersburg, MD 20899

Prepared for National Institute of Justice Office of Justice Programs U.S. Department of Justice Washington, DC 20531 


\section{ABOUT THE TECHNOLOGY ASSESSMENT PROGRAM}

The Technology Assessment Program is sponsored by the Office of Development, Testing, and Dissemination of the National Institute of Justice (NIJ), U.S. Department of Justice. The program responds to the mandate of the Justice System Improvement Act of 1979, which created NIJ and directed it to encourage research and development to improve the criminal justice system and to disseminate the results to Federal, State, and local agencies.

The Technology Assessment Program is an applied research effort that determines the technological needs of justice system agencies, sets minimum performance standards for specific devices, tests commercially available equipment against those standards, and disseminates the standards and the test results to criminal justice agencies nationwide and internationally.

The program operates through:

The Technology Assessment Program Advisory Council (TAPAC) consisting of nationally recognized criminal justice practitioners from Federal, State, and local agencies, which assesses technological needs and sets priorities for research programs and items to be evaluated and tested.

The Office of Law Enforcement Standards (OLES) at the National Institute of Standards and Technology, which develops voluntary national performance standards for compliance testing to ensure that individual items of equipment are suitable for use by criminal justice agencies. The standards are based upon laboratory testing and evaluation of representative samples of each item of equipment to determine the key attributes, develop test methods, and establish minimum performance requirements for each essential attribute. In addition to the highly technical standards, OLES also produces user guides that explain in nontechnical terms the capabilities of available equipment.

The Technology Assessment Program Information Center (TAPIC), operated by a grantee, which supervises a national compliance testing program conducted by independent agencies. The standards developed by OLES serve as performance benchmarks against which commercial equipment is measured. The facilities, personnel, and testing capabilities of the independent laboratories are evaluated by OLES prior to testing each item of equipment, and OLES helps the Information Center staff review and analyze data. Test results are published in Consumer Product Reports designed to help justice system procurement officials make informed purchasing decisions.

Publications issued by the National Institute of Justice, including those of the Technology Assessment Program, are available from the National Criminal Justice Reference Service (NCJRS), which serves as a central information and reference source for the Nation's criminal justice community. For further information, or to register with NCJRS, write to the National Institute of Justice, National Criminal Justice Reference Service, Washington, DC 20531.

Charles B. DeWitt, Director

National Institute of Justice

The Assistant Attorney General, Office of Justice Programs, establishes the policies and priorities, and manages and coordinates the activities of the Bureau of Justice Assistance, Bureau of Justice Statistics, National Institute of Justice, Office of Juvenile Justice and Delinquency Prevention, and the Office for Victims of Crime. 


\section{NISTIR 4927}

\section{Limited Tests to Investigate Whether the Size of Body Armor Samples Influences Ballistic Test Results}

\section{Keith R. Eberhardt}

Computing and Applied Mathematics Laboratory Statistical Engineering Division

\section{Lawrence K. Eliason}

Electronics and Electrical Engineering Laboratory Office of Law Enforcement Standards

U.S. DEPARTMENT OF COMMERCE Technology Administration National Institute of Standards and Technology

Gaithersburg, MD 20899

Prepared for

National Institute of Justice Office of Justice Programs U.S. Department of Justice Washington, DC 20531

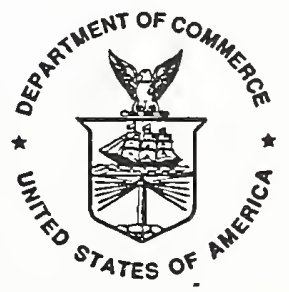

U.S. DEPARTMENT OF COMMERCE Barbara Hackman Franklin, Secretary

TECHNOLOGY ADMINISTRATION Robert M. White, Under Secretary for Technology

NATIONAL INSTITUTE OF STANDARDS AND TECHNOLOGY

John W. Lyons, Director 


\section{ACKNOWLEDGMENTS}

This report was prepared by the Office of Law Enforcement Standards (OLES) of the National Institute of Standards and Technology under the direction of Daniel E. Frank, Manager, Protective Equipment Program, and Lawrence K. Eliason, Director of OLES. Daniel E. Frank and Nathaniel E. Waters performed the research and collected the data. The research was sponsored by the National Institute of Justice, David Boyd, Director, Science and Technology Division. The technical effort to develop this report was conducted under Interagency Agreement LEAA-J-IAA-021-3, Project No. 9202. 


\section{FOREWORD}

The Office of Law Enforcement Standards (OLES) of the National Institute of Standards and Technology (formerly the National Bureau of Standards) furnishes technical support to the National Institute of Justice program to strengthen law enforcement and criminal justice in the United States. OLES's function is to conduct research that will assist law enforcement and criminal justice agencies in the selection and procurement of quality equipment.

OLES is: (1) Subjecting existing equipment to laboratory testing and evaluation and (2) conducting research leading to the development of several series of documents, including national voluntary equipment standards, user guides, and technical reports.

This document presents the results of a limited series of experiments conducted by the OLES in an attempt to determine whether ballistic tests conducted on different sizes of armor samples were representative of the armor population as a whole. Tests were conducted on large, medium, and small vests using both widely spaced shot patterns and closely spaced shot patterns. The results were then statistically analyzed.

Technical comments and suggestions concerning this document are invited from all interested parties. They may be addressed to the Office of Law Enforcement Standards, National Institute of Standards and Technology, Gaithersburg, MD, 20899.

Lawrence K. Eliason, Director Office of Law Enforcement Standards 


\section{TABLE OF CONTENTS}

Page

Foreword $\ldots \ldots \ldots \ldots \ldots \ldots \ldots \ldots \ldots \ldots \ldots \ldots \ldots$ iii

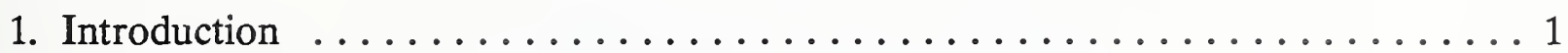

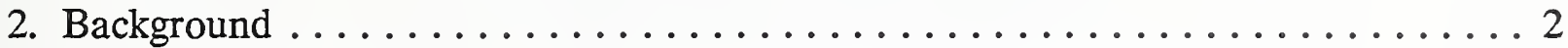

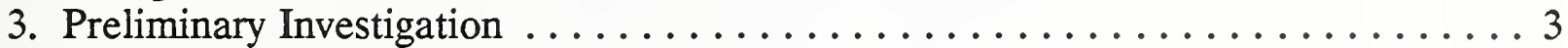

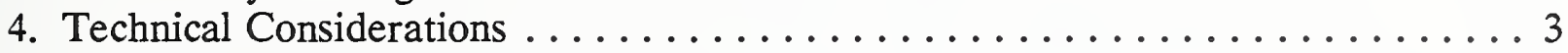

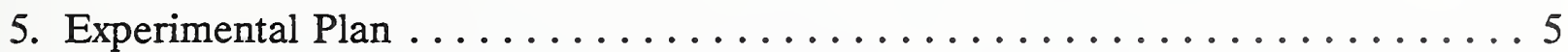

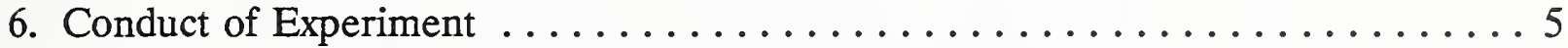

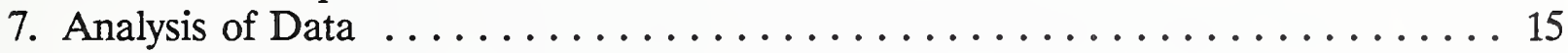

8. Conclusions and Recommendations . ........................ 21

Appendix A-Impact Location Spacing . . . . . . . . . . . . . . . A-1 


\section{LIST OF FIGURES}

Page

Figure 1. Test sequence and impact locations ................. 4

Figure 2. Test matrix. Groups A, C, and D impacted with minimal spacing.

Group B impacted with maximum spacing ............ 6

Figure 3. Drawing of impact location template for minimal spacing

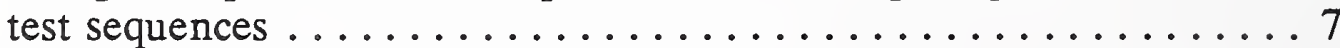

Figure 4. Sample 11 front panel following completion of the six-impact

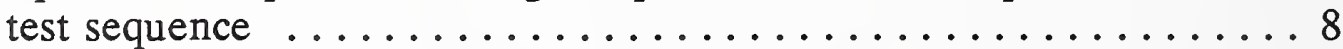

Figure 5. Sample 11 back panel following completion of the six-impact

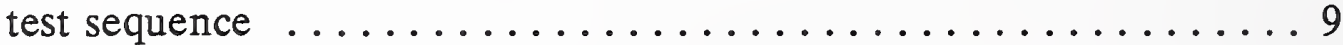

Figure 6. Penetration distribution for the four test groups; 0 indicates no penetrations, numbers identify the impact locations of

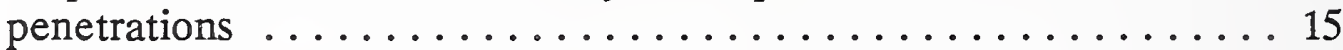

Figure A-1. Impact location spacing dimensions $\ldots \ldots \ldots \ldots \ldots \ldots \ldots \ldots$ A-1

\section{LIST OF TABLES}

Table 1. Test results, group A samples .................... 11

Table 2. Test results, group B samples ..................... 12

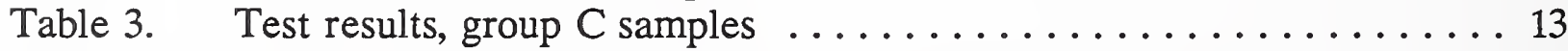

Table 4. Test results, group $\mathrm{D}$ samples ..................... 14

Table 5. Summary of tests for effect of vest size on penetration rate ....... 16

Table 6. Data summary on per-panel basis .................. 16

Table 7. Analysis of maximum likelihood estimates ................ 17

Table 8. Confidence intervals, corresponding to three test parameters, for estimated change in probability of failing an NIJ-03 test . . . . . 19

Table 9. Illustration of confidence interval widths obtainable by increasing number of test panels, for case of shot pattern size (maximum vs.

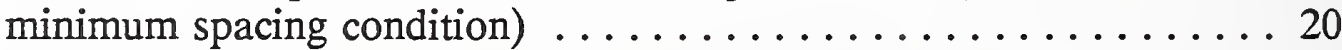

Table 10. Illustration of confidence interval widths obtainable by increasing number of test panels, for case of nominal vest size (size 50/52

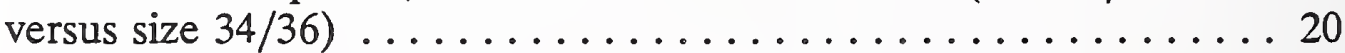

Table A-1. Front panel impact location spacing ................ A-2

Table A-2. Back panel impact location spacing ................ A-2 


\title{
Limited Tests to Investigate Whether the Size of Body Armor Samples Influences Ballistic Test Results
}

\author{
Keith R. Eberhardt ${ }^{*}$ and Lawrence K. Eliason ${ }^{* *}$ \\ National Institute of Standards and Technology \\ Gaithersburg, MD 20899
}

\begin{abstract}
A limited series of tests was conducted to investigate whether the size of body armor samples influences ballistic results. An analysis of the results was conducted, and none of the factors evaluated (the size of the sample, the size of the impact pattern, or front-versus-back armor panels) were found to be statistically significant. However, the confidence intervals were large and the possibility exists that these factors could have an effect on test results. The analysis determined that a major experiment would be necessary to quantify effects. It is concluded that the size of test samples, alone, is not critical to the results obtained from tests in accordance with NIJ Standard-0101.03.
\end{abstract}

It appeared that the size of the shot pattern was more likely to have an effect on the results of ballistic testing, than the other factors that were investigated. The expense of the experiments required to quantify the effects of armor size and shot pattern size was not believed to be warranted, for both can be avoided by not conducting tests on small size armor samples.

\section{INTRODUCTION}

This report discusses the results of a limited series of experiments conducted by the Office of Law Enforcement Standards (OLES) in an attempt to determine whether the size of body armor samples influences the results of ballistic tests of armor.

To the present time, literally hundreds of models of body armor have been subjected to ballistic tests. Recently test results have been questioned on the basis that the physical size of the test sample influenced the results of the testing. Thus, the issue was investigated.

The study described in this report was undertaken when it was not possible to ascertain whether the size of armor samples correlated with test results, based upon independent testing laboratory records. This issue has not been the topic of published research. Lacking

\footnotetext{
Statistical Engineering Division, Computing and Applied Mathematics Laboratory.

** Office of Law Enforcement Standards, Electronics and Electrical Engineering Laboratory.
} 
such information, OLES recommended undertaking a limited study with the expectation that any pronounced trends, as a function of test specimen size, could be detected.

\section{BACKGROUND}

The National Institute of Justice (NIJ) promulgated the third revision of its voluntary national standard, NIJ Standard-0101.03, "Ballistic Resistance of Police Body Armor," in April 1987. The revised standard was developed by the Office of Law Enforcement Standards (OLES), then the Law Enforcement Standards Laboratory.

Following promulgation of the revised standard, NIJ conducted a major testing program, starting in the fall of 1987 , to determine which models of domestic body armor fully complied with the requirements of NIJ Standard-0101.03. Only 34 of 84 models of armor tested by an independent testing laboratory, H. P. White Laboratory, Inc., Street, Maryland, were found to fully comply with the requirements of the standard. In response to the high rate of noncompliance, claims were made that the test methods lacked reproducibility. The criticism of the standard has continued to the present time, and in 1991 the U.S. Congress Office of Technology Assessment (OTA) initiated an independent study of the NIJ standard and the issues raised by industry. The final report of the OTA study was issued during the summer of 1992.

Subsequent to the NIJ-funded compliance testing program of 1987, armor manufacturers have continued to have their products tested for compliance with the NIJ standard. In addition, law enforcement agencies have begun increasingly to have samples of the armor they purchase subjected to acceptance testing by H. P. White Laboratory, Inc. Also, some law enforcement agencies have H. P. White Laboratory, Inc. conduct tests of armor that has been issued to officers and worn for several years to verify continued compliance with the requirements of NIJ Standard-0101.03.

The NIJ standard specifies that the samples submitted for testing in accordance with the standard shall fit a chest circumference of 46 to 48 in (size 46/48); however, this is caveated to indicate that the size selected is for the purpose of ensuring that two six-impact ballistic test sequences can be conducted on a single armor part.

Approximately two years ago, some manufacturers began to challenge test results obtained during departmental testing, particularly in cases of tests of used armor, stating that the results were not valid because a size other than the specified size $46 / 48$ sample was tested. Since such challenges were infrequent, NIJ gave little credence to the manufacturer claims.

Toward the end of 1991, the testing laboratory began to annotate its test reports to police departments, in cases where armor did not comply with the requirements of the standard and the sample tested was smaller than the specified size. This action served to 
elevate concerns that the size of the armor sample might influence test results. Based upon the fact that there was increasing concern over sample size, OLES suggested that the issue of armor size should be addressed.

\section{PRELIMINARY INVESTIGATION}

The NIJ Body Armor Compliance Testing Program is administered by the Technology Assessment Program Information Center (TAPIC), Rockville, Maryland. Manufacturers negotiate testing contracts and schedules directly with the NIJ approved independent testing laboratory, $\mathrm{H}$. P. White Laboratory, Inc.

The actual test samples are submitted to TAPIC, which maintains a chain of custody for all samples. TAPIC delivers the manufacturer samples to $H$. P. White, receives the final test report from $\mathrm{H}$. P. White together with the test sample following testing. TAPIC issues letters of compliance to manufacturers for models found to meet the requirements of NIJ Standard-0101.03. Tested samples are archived by TAPIC, and complete test results are maintained by TAPIC. The data sheets of the H. P. White test results contain full particulars of the individual armor model that has been tested, including the marked size of the armor sample.

Since the TAPIC records include test reports concerning all armor tested for compliance since NIJ Standard-0101.03 was issued in 1987, OLES originally felt that a review of these records could suffice to establish a trend based upon armor sample size if larger armor was more prone to demonstrate compliance than small sizes.

Unfortunately, the size designation on manufacturer labels do not universally record the size in chest circumference, such as size 46 , etc. In those cases where armor size was specified in chest circumference it appeared that approximately 23 percent of the armor models submitted were size 44 or smaller. It was not possible, however, to compare rates of compliance and noncompliance based upon specimen size.

Since the test reports did not enable the desired analysis, OLES recommended that an experimental program be undertaken.

\section{TECHNICAL CONSIDERATIONS}

The ballistic test sequence of NIJ Standard-0101.03 consists of six impacts of each of two different bullets. Figure 1 shows the shot sequence and general impact location of each of the six required bullet impacts, presently used for compliance testing. Four of these impacts are normal to the surface of the armor, and two locations (4 and 5) impact at an angle of incidence of $30^{\circ}$ to the surface of the armor, both fired toward the center of the armor part. 
While it is generally accepted that ballistic-resistant fabrics prevent the penetration of bullets through distribution of the impact energy along the length of the individual yarns, the precise mechanism has not been fully determined.

The standard shows shots 4,5 , and 6 in a row across the armor part, however, since the individual yarns are subjected to tensile stress over their entire length, at least to some extent, through interaction with the bullet at the time of impact, it is reasonable to assume that the impact stress weakens the yarn involved in the impact, and could increase the probability of penetration if the yarn were impacted at a different location along its length a second or third time. It was for this reason that NIJ agreed to move the impact locations of shot 4, 5, and 6 (see fig. 1) to preclude the impact of more than one bullet on a single row of horizontal yarns.

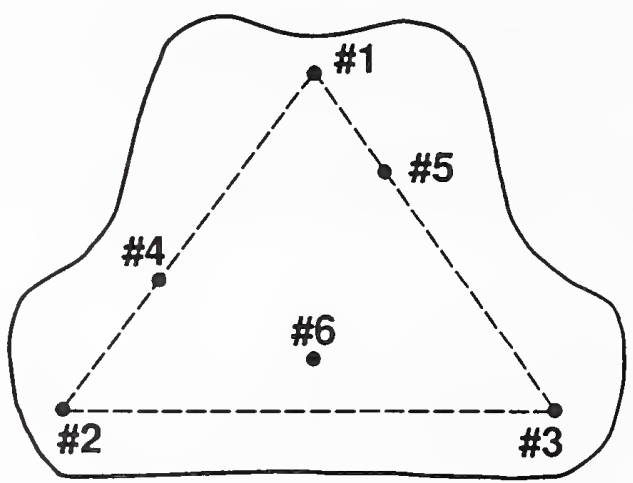

Figure 1. Test sequence and impact locations.

The ballistic element of soft body armor consists of multiple layers of fabric. Clearly, while large and small elements of the same design have the same areal density (weight per unit area), a large element contains more ballistic material than does a smaller one. Since the impact energy of a bullet may be distributed throughout the ballistic element, it is possible that a smaller ballistic element may have a greater probability of penetration than a large one simply because it has less total material to absorb the impact energy.

Neither the first failure mechanism, cumulative damage through multiple impacts along a single row of fabric yarn, nor the second, energy absorption of a function of total panel weight, has been the topic of published laboratory study results, to our knowledge.

Finally, it is possible that a small ballistic element, as a consequence of closer shot placement during the NIJ six shot sequence, may exhibit greater rates of penetration than that of a larger pattern on a larger ballistic element. 


\section{EXPERIMENTAL PLAN}

A manufacturer that embargoed a production lot of armor two years ago provided a portion of that lot of armor to OLES for use in tests to compare the three mounting fixtures for NIJ Standard-0101.03 testing (see NIJ Report 100-91, A Comparison of the Use of Three Different Mounting Fixtures for Ballistic Tests of Body Armor). The balance of the armor lot was donated to OLES for the current experiments.

Since the armor to be used in this experiment was originally a departmental purchase, the size distribution of the total lot reflected the size of individual officers within the department. The size distribution, then determined the extent to which individual tests of variables could be replicated. In the final analysis, we were limited to two replications (front and back panels) of four test conditions replicated four times, a total of 16 vests or 32 panels.

The armor used as test specimens met two important criteria for a statistical analysis; based upon the earlier tests. First, it is marginal with respect to the performance requirements of NIJ Standard-0101.03 so that we could expect some penetrations. Second, the ballistic-resistant fabrics used in construction were from single lots of material; i.e., the ballistic elements were a reasonably homogenous sample.

The experiment included four specific test variables. Eight specimens of size 42/44, the largest size available in quantity from the armor lot used for the test program, were separated into two groups, half of which were to be subjected to the NIJ six-shot sequence using the maximum possible spacing of the impacts and half would be impacted with close spacing, referred to throughout this report as minimum impact spacing. It would have been possible to use a smaller pattern, while still maintaining the required spacing between impacts, however, this was not done in order to avoid unfair hits. A third group of four large size samples (including one size 50/52 long) would be subjected to the NIJ six-shot sequence using the minimum impact spacing, and a fourth group of four samples smaller than size $42 / 44$ would be impacted with the same minimum impact spacing. In all cases, the impact would be held to armor type II impact velocities and only one bullet, the .357 jacketed soft point would be used.

Because the test results called into question to date have all been conducted using the flat clay block mounting fixture, that fixture was used for this experiment.

\section{CONDUCT OF EXPERIMENT}

The test specimens were drawn at random from the body armor available for test based upon sample size. The individual armor samples were numbered from 1 to 16 , separated into four groups, and further separated into two separate sets, front and back. 
The test sequence followed the matrix shown in figure 2. The armor was tested in ascending order of the sample number. Three of the four sample groups (A, C, and D) were impacted following a fixed minimal spacing impact sequence shown in figure 3 . The intended impact locations were marked with chalk using a template of the dimensions and locations shown in figure 3. The fourth sample group, B, was marked to locate intended locations without the aid of a template. In this case, locations were selected $7.6 \mathrm{~mm}$ ( $3 \mathrm{in})$ from the edge of the armor panel so as to result in the maximal pattern for the armor part. The size of each set of armor, which included long (L), regular (R), and short (S) neck to waist lengths, is noted in tables 1 through 4 , as is the shot pattern.

The test bullets were all .357 jacketed soft point, $10.2 \mathrm{~g}$. Each test round was hand loaded. The laboratory set-up was in accordance with the requirements of NIJ Standard0101.03; the test weapon (a Mann barrel) was positioned $5 \mathrm{~m}$ from the clay backing material, with the chronograph screens 2 and $3 \mathrm{~m}$ in front of the test weapon muzzle, $(1 \mathrm{~m}$ apart).

Impact locations were controlled by moving the sample horizontally and vertically to align the premarked impact location with the spot from a laser designator.

The test samples were attached to the flat clay block using two horizontal and two vertical elastic straps as shown in figure 4 (armor front panel) and figure 5 (armor back panel). In both cases the photographs of the armor were taken immediately following the test sequence. The elastic straps were positioned around the armor part so that the straps formed a box around the intended impact location for each impact in the test sequence; i.e., the locations of the straps were moved prior to each impact.

During the test of the back panel armor sample 1 , impact 4 was inadvertently aligned with the chalk mark for location 6 . The location of the remaining impact locations were adjusted, and the test sequence continued. The panel withstood the six impacts without penetration.

$\begin{array}{cccc}\begin{array}{c}\text { Test Group A } \\ \text { Sample No. }\end{array} & \begin{array}{c}\text { Test Group B } \\ \text { Sample No. }\end{array} & \begin{array}{c}\text { Test Group C } \\ \text { Sample No. }\end{array} & \begin{array}{c}\text { Test Group D } \\ \text { Sample No. }\end{array} \\ \text { 1F } & 2 \mathrm{~F} & 3 \mathrm{~F} & 4 \mathrm{~F} \\ \text { 8F } & \text { 7F } & 6 \mathrm{~F} & 5 \mathrm{~F} \\ \text { 9F } & 10 \mathrm{~F} & 11 \mathrm{~F} & 12 \mathrm{~F} \\ \text { 16F } & 15 \mathrm{~F} & 14 \mathrm{~F} & 13 \mathrm{~F} \\ & & & \\ \text { Test Group A } & \text { Test Group B } & \text { Test Group C } & \text { Test Group D } \\ \text { Sample No. } & \text { Sample No. } & \text { Sample No. } & \text { Sample No. } \\ \text { 1A-B } & \text { 2B } & \text { 3B } & 4 \mathrm{~B} \\ \text { 8B } & \text { 7B } & 6 \mathrm{~B} & \text { 5B } \\ \text { 9B } & \text { 10B } & \text { 11B } & 12 \mathrm{~B} \\ \text { 16B } & \text { 15B } & 14 \mathrm{~B} & 13 \mathrm{~B}\end{array}$

Figure 2. Test matrix. Groups A, C, and D impacted with minimal spacing. Group B impacted with maximum spacing. 


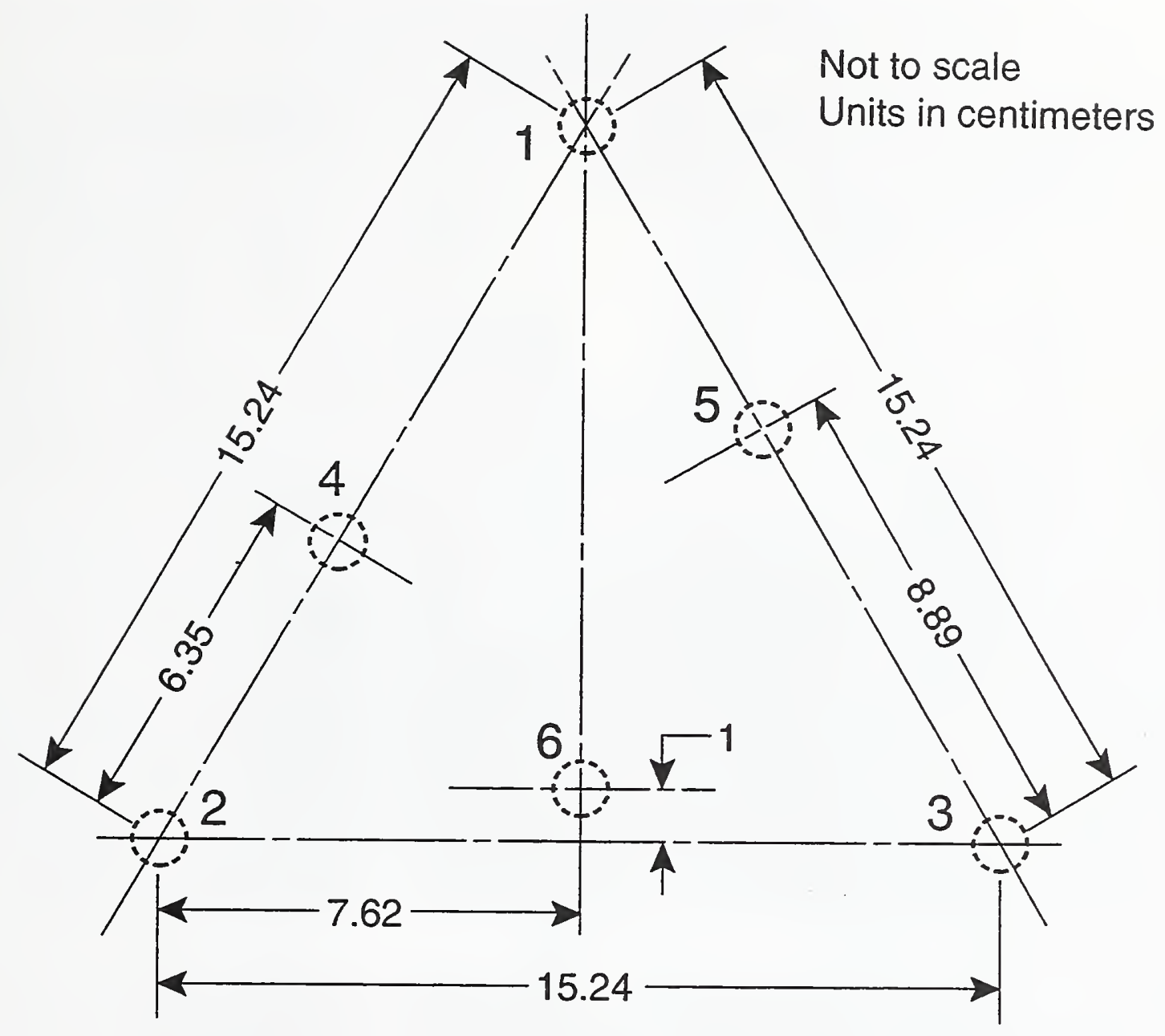

Figure 3. Drawing of impact location template for minimal spacing test sequences.

At the suggestion of the NIST statistician, this test was repeated using a new back from armor not scheduled for inclusion in the test, and the second set of data identified as 1A-B was used in the analysis discussed in the next section of this report.

Likewise the first impact on sample $12 \mathrm{~F}$ was at a velocity of only $414 \mathrm{~m} / \mathrm{s}$. The first impact was repeated at the correct velocity and the full test sequence was completed. A bullet impact that is below the minimum required velocity is considered to be an unfair hit for testing purposes unless it penetrates the armor and the NIJ standard requires that such an impact be repeated, at or above the minimum velocity, at the same general impact location, a minimum of $5.08 \mathrm{~cm} \mathrm{(2} \mathrm{in)} \mathrm{from} \mathrm{the} \mathrm{unfair} \mathrm{hit.} \mathrm{At} \mathrm{the} \mathrm{suggestion} \mathrm{of} \mathrm{the} \mathrm{NIST}$ statistician, the low velocity data point was also excluded from the analysis.

In all cases, the point of impact of the test bullet was within the circle (approximately $1 \mathrm{~cm}$ diameter) marked on the armor using the template, or marked without the use of a template. 


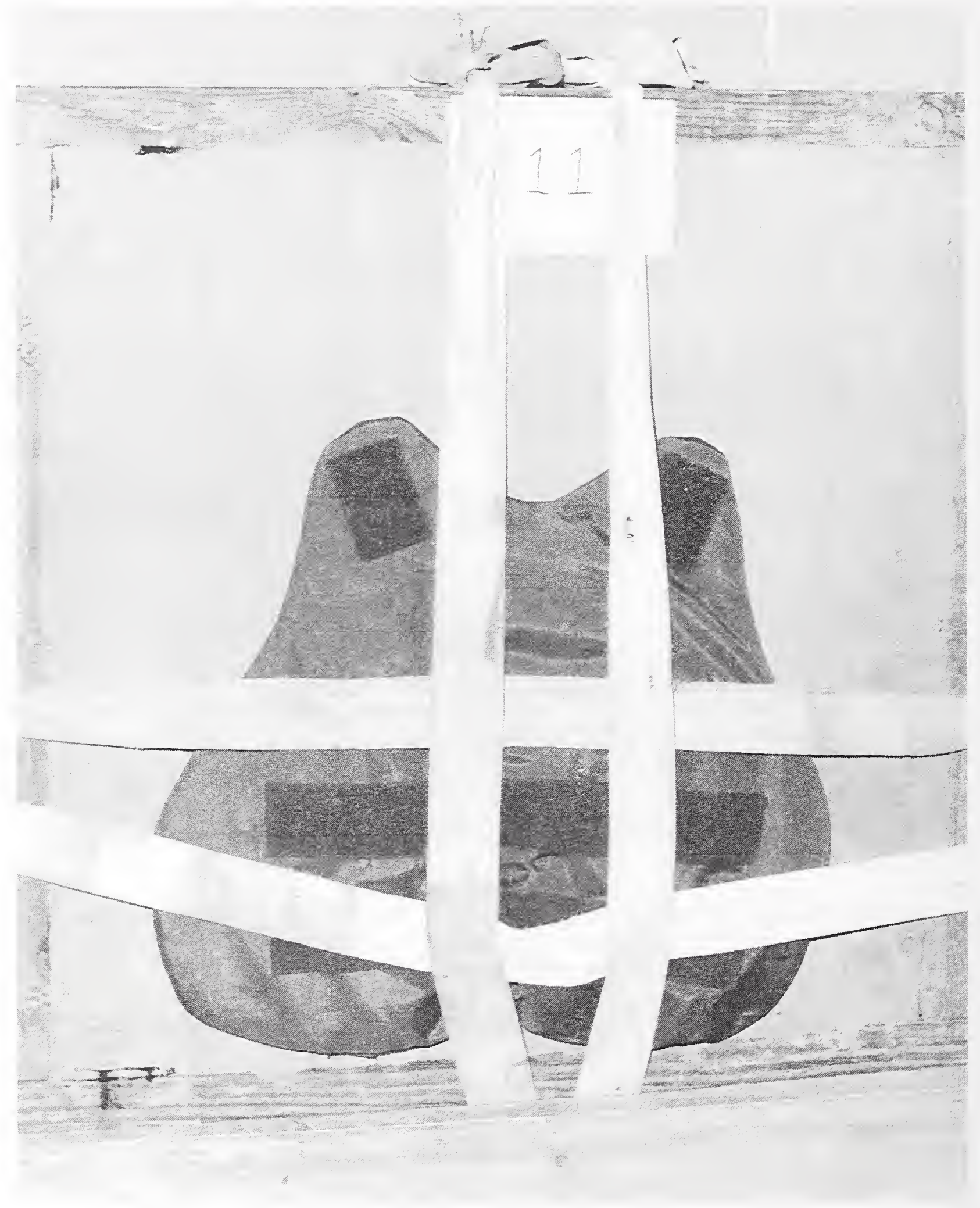

Figure 4. Sample 11 front panel following completion of the six-impact test sequence. 


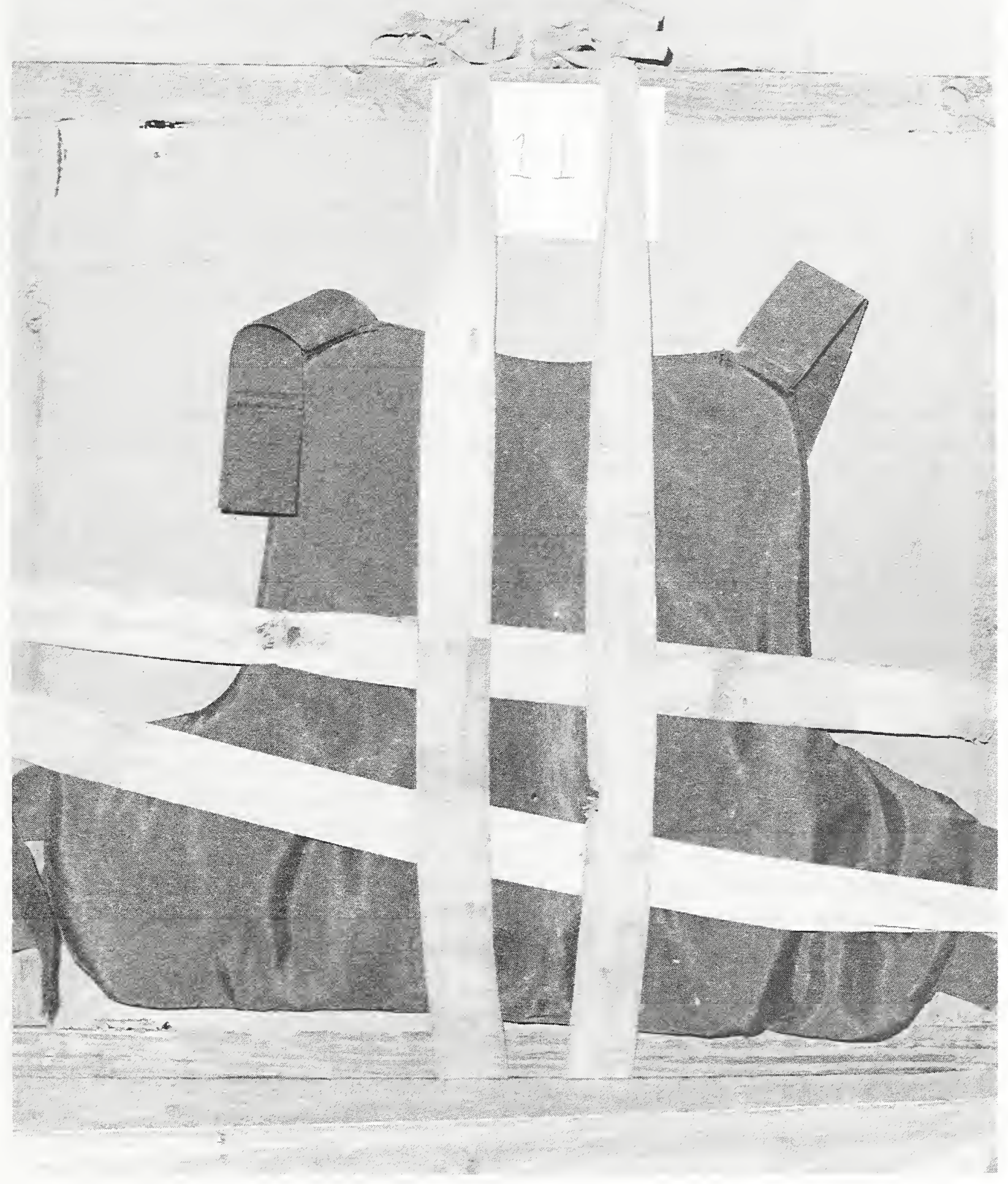

Figure 5. Sample 11 back panel following completion of the six-impact test sequence. 
The average velocity of the 96 test bullets fired in the testing of armor front panels was $433.5 \mathrm{~m} / \mathrm{s}$ with a standard deviation of $3.44 \mathrm{~m} / \mathrm{s}$; the average velocity of the 96 test rounds fired in the testing of the armor back panels was $432.5 \mathrm{~m} / \mathrm{s}$ with a standard deviation of $3.05 \mathrm{~m} / \mathrm{s}$. The velocity range for the tests of front panels was 426 to $441 \mathrm{~m} / \mathrm{s}$, while that of the tests of back panels was 425 to $444 \mathrm{~m} / \mathrm{s}$. The impact velocity range required by NIJ Standard-0101.03 for type II armor is 425 to $440 \mathrm{~m} / \mathrm{s}$. This series of experiments included a total of 199 test rounds; one was below the minimum impact velocity, and two exceeded the upper limit by $1 \mathrm{~m} / \mathrm{s}$ and $4 \mathrm{~m} / \mathrm{s}$. The data point from the one low velocity impact was excluded from the analysis, while the data points from the two high-velocity impacts were included in the analysis. The six data points for panel 1B, as mentioned above, were excluded from the analysis; thus 192 data points of the 199 obtained in the experiments were included in the analysis.

For purposes of the NIJ compliance testing program, the laboratory was instructed to classify a bullet that is caught in the last layer of ballistic material, but protrudes from the back surface of this layer, as a penetration. There were two such instances during this series of tests, both of which were classified as penetrations for the analysis.

The test results of this study are presented in tables 1 through 4 . There were seven penetrations of the front panels and seven penetrations of the back panels for an overall penetration rate of 7.29 percent. The distribution of the penetrations within the four test groups is shown in figure 6 . There was a single penetration at impact location 2 , with three occurring at impact location 3, three at impact location 5, and seven at impact location 6 .

Visually, there was some movement of the ballistic panels within the carriers as a consequence of bullet impact. The extent of ballistic panel movement was similar for all of the armor that was tested. In order to determine whether this movement resulted in impacts closer to one another than the $5.1 \mathrm{~cm}$ ( 2 in) spacing specified in the standard, the spacings between impact locations 4,5 , and 6 were measured following the testing. Two of the 16 front panels that were tested were found to have impact spacings between impact locations 4 and 5 less than $5.1 \mathrm{~cm}$. These were sample 3F, with a spacing of $4.8 \mathrm{~cm}$, and sample $12 \mathrm{~F}$, with a spacing of $3.2 \mathrm{~cm}$. Sample $3 \mathrm{~F}$ was penetrated by a single bullet at location 5 , while sample $12 \mathrm{~F}$ had no penetrations.

Three of the back panels had impact spacings less than $5.1 \mathrm{~cm} ; 1 \mathrm{~A}-\mathrm{B}$ with spacing of $4.8 \mathrm{~cm}$ between impact locations 4 and 5 , which had a single penetration at location 6 (7.6 cm from impact location 4 and $8.6 \mathrm{~cm}$ from impact location 5); 12B with a spacing of $4.4 \mathrm{~cm}$ between impact locations 4 and 6, with no penetrations; and 16B with a spacing of $4.8 \mathrm{~cm}$ between impact locations 4 and 6 , which also had no penetrations.

Only one of the 14 penetrations was potentially attributable to the spacing between two adjacent impacts. 
Table 1. Test results, group A samples.

\begin{tabular}{|c|c|c|c|c|c|}
\hline $\begin{array}{l}\text { Vest } \\
\text { I.D. }\end{array}$ & $\begin{array}{l}\text { Shot } \\
\text { Location }\end{array}$ & $\begin{array}{c}\text { Impact } \\
\text { Velocity }(\mathrm{m} / \mathrm{s})\end{array}$ & Penetration & Size & $\begin{array}{l}\text { Shot } \\
\text { Pattern }\end{array}$ \\
\hline $1 F$ & 1 & 438 & $\mathbf{N}$ & $42 / 44 \mathrm{~L}$ & Min \\
\hline " & 2 & 431 & $\mathrm{~N}$ & $n$ & n \\
\hline n & 3 & 432 & $\mathrm{~N}$ & n & n \\
\hline n & 4 & 429 & $\mathrm{~N}$ & n & $n$ \\
\hline$n$ & 5 & 430 & $\mathrm{Y}$ & n & $n$ \\
\hline n & 6 & 427 & $\mathrm{Y}$ & n & $n$ \\
\hline $8 \mathrm{~F}$ & 1 & 435 & $\mathbf{N}$ & $42 / 44 R$ & Min \\
\hline$n$ & 2 & 432 & N & n & $n$ \\
\hline$n$ & 3 & 433 & $\mathrm{~N}$ & $n$ & n \\
\hline n & 4 & 437 & $\mathrm{~N}$ & n & n \\
\hline n & 5 & 435 & $\mathbf{N}$ & " & n \\
\hline$n$ & 6 & 430 & $\mathrm{~N}$ & n & n \\
\hline $9 \mathrm{~F}$ & 1 & 436 & $\mathbf{N}$ & $42 / 44 R$ & Min \\
\hline$n$ & 2 & 439 & N & n & $n$ \\
\hline n & 3 & 431 & $\mathrm{~N}$ & n & n \\
\hline " & 4 & 434 & $\mathbf{N}$ & n & n \\
\hline$n$ & 5 & 435 & $\mathrm{~N}$ & n & $n$ \\
\hline n & 6 & 432 & $\mathrm{~N}$ & $n$ & $n$ \\
\hline $16 \mathrm{~F}$ & 1 & 437 & $\mathrm{~N}$ & $42 / 44 R$ & Min \\
\hline$n$ & 2 & 437 & $\mathrm{~N}$ & n & n \\
\hline " & 3 & 436 & $\mathrm{Y}$ & " & n \\
\hline n & 4 & 431 & $\mathrm{~N}$ & n & $n$ \\
\hline " & 5 & 437 & $\mathrm{~N}$ & $n$ & n \\
\hline " & 6 & 427 & $\mathrm{Y}$ & $n$ & $n$ \\
\hline $1 \mathrm{~A}-\mathrm{B}$ & 1 & 428 & $\mathrm{~N}$ & $42 / 44 R$ & Min \\
\hline " & 2 & 433 & $\mathrm{~N}$ & n & $n$ \\
\hline$n$ & 3 & 429 & $\mathrm{~N}$ & n & n \\
\hline " & 4 & 439 & $\mathrm{~N}$ & n & n \\
\hline " & 5 & 433 & $\mathrm{~N}$ & n & " \\
\hline " & 6 & 433 & $\mathrm{Y}$ & n & n \\
\hline $8 \mathrm{~B}$ & 1 & 444 & $\mathrm{~N}$ & $42 / 44 R$ & Min \\
\hline$"$ & 2 & 437 & $\mathrm{~N}$ & " & n \\
\hline$n$ & 3 & 435 & $\mathrm{~N}$ & n & n \\
\hline n & 4 & 435 & $\mathrm{~N}$ & n & n \\
\hline " & 5 & 436 & N & $n$ & $n$ \\
\hline$n$ & 6 & 432 & $\mathrm{~N}$ & " & n \\
\hline $9 \mathrm{~B}$ & 1 & 434 & $\mathrm{~N}$ & $42 / 44 R$ & Min \\
\hline$"$ & 2 & 433 & $\mathrm{Y}$ & $n$ & $n$ \\
\hline " & 3 & 430 & $\mathbf{N}$ & " & " \\
\hline$"$ & 4 & 425 & $\mathrm{~N}$ & " & " \\
\hline " & 5 & 433 & $\mathbf{N}$ & " & " \\
\hline " & 6 & 433 & $\mathrm{Y}$ & n & " \\
\hline $16 \mathrm{~B}$ & 1 & 432 & $\mathrm{~N}$ & $42 / 44 R$ & Min \\
\hline " & 2 & 432 & $\mathrm{~N}$ & n & " \\
\hline n & 3 & 431 & $\mathrm{~N}$ & " & $"$ \\
\hline n & 4 & 435 & $\mathrm{~N}$ & n & $n$ \\
\hline$n$ & 5 & 435 & $\mathrm{~N}$ & n & $"$ \\
\hline n & 6 & 433 & $\mathrm{~N}$ & n & $n$ \\
\hline
\end{tabular}


Table 2. Test results, group B samples.

\begin{tabular}{|c|c|c|c|c|c|}
\hline $\begin{array}{l}\text { Vest } \\
\text { I.D. }\end{array}$ & $\begin{array}{c}\text { Shot } \\
\text { Location }\end{array}$ & $\begin{array}{c}\text { Impact } \\
\text { Velocity }(\mathrm{m} / \mathrm{s})\end{array}$ & Penetration & Size & $\begin{array}{c}\text { Shot } \\
\text { Pattern }\end{array}$ \\
\hline $2 \mathrm{~F}$ & 1 & 441 & $\mathrm{~N}$ & $42 / 44 R$ & $\operatorname{Max}$ \\
\hline$"$ & 2 & 435 & $\mathrm{~N}$ & n & $n$ \\
\hline " & 3 & 435 & $\mathrm{~N}$ & " & n \\
\hline " & 4 & 432 & $\mathrm{~N}$ & " & n \\
\hline " & 5 & 429 & $\mathrm{~N}$ & $n$ & n \\
\hline$"$ & 6 & 436 & $\mathrm{~N}$ & $n$ & $"$ \\
\hline $7 \mathrm{~F}$ & 1 & 437 & $\mathrm{~N}$ & $42 / 44 R$ & $\operatorname{Max}$ \\
\hline " & 2 & 432 & $\mathrm{~N}$ & $n$ & $n$ \\
\hline " & 3 & 437 & $\mathrm{~N}$ & $n$ & " \\
\hline n & 4 & 432 & $\mathrm{~N}$ & " & " \\
\hline " & 5 & 431 & $\mathrm{~N}$ & n & $"$ \\
\hline$n$ & 6 & 435 & $\mathrm{~N}$ & $"$ & " \\
\hline $10 \mathrm{~F}$ & 1 & 433 & $\mathrm{~N}$ & $42 / 44 R$ & $\operatorname{Max}$ \\
\hline " & 2 & 439 & $\mathrm{~N}$ & n & " \\
\hline n & 3 & 437 & $\mathrm{~N}$ & $n$ & " \\
\hline n & 4 & 428 & $\mathrm{~N}$ & " & n \\
\hline n & 5 & 433 & $\mathrm{~N}$ & n & " \\
\hline$n$ & 6 & 433 & $\mathrm{~N}$ & $n$ & $"$ \\
\hline $15 \mathrm{~F}$ & 1 & 430 & $\mathrm{~N}$ & $42 / 44 R$ & Max \\
\hline$"$ & 2 & 436 & $\mathrm{~N}$ & $n$ & " \\
\hline n & 3 & 432 & $\mathrm{~N}$ & n & " \\
\hline n & 4 & 432 & $\mathrm{~N}$ & n & " \\
\hline$"$ & 5 & 433 & $\mathrm{~N}$ & " & n \\
\hline$n$ & 6 & 433 & $\mathrm{~N}$ & $n$ & $n$ \\
\hline $2 \mathrm{~B}$ & 1 & 433 & $\mathrm{~N}$ & $42 / 44 R$ & Max \\
\hline$"$ & 2 & 438 & $\mathrm{~N}$ & n & \\
\hline$n$ & 3 & 431 & $\mathrm{~N}$ & n & n \\
\hline " & 4 & 430 & $\mathrm{~N}$ & " & n \\
\hline$n$ & 5 & 433 & $\mathrm{~N}$ & $n$ & $n$ \\
\hline$"$ & 6 & 431 & $\mathrm{~N}$ & $n$ & $"$ \\
\hline $7 \mathrm{~B}$ & 1 & 431 & $\mathrm{~N}$ & $42 / 44 R$ & $\operatorname{Max}$ \\
\hline$n$ & 2 & 433 & $\mathrm{~N}$ & $n$ & " \\
\hline " & 3 & 429 & $\mathrm{~N}$ & n & n \\
\hline " & 4 & 431 & $\mathrm{~N}$ & n & n \\
\hline$"$ & 5 & 431 & $\mathrm{~N}$ & n & $"$ \\
\hline$"$ & 6 & 439 & N & $n$ & $"$ \\
\hline $10 \mathrm{~B}$ & 1 & 438 & $\mathrm{~N}$ & $42 / 44 R$ & $\operatorname{Max}$ \\
\hline " & 2 & 429 & $\mathrm{~N}$ & n & " \\
\hline n & 3 & 435 & $\mathrm{~N}$ & $n$ & $"$ \\
\hline n & 4 & 434 & $\mathrm{~N}$ & $n$ & " \\
\hline " & 5 & 434 & $\mathrm{~N}$ & $n$ & $n$ \\
\hline$n$ & 6 & 435 & $\mathrm{Y}$ & $n$ & $n$ \\
\hline $15 \mathrm{~B}$ & 1 & 435 & $\mathrm{~N}$ & $42 / 44 R$ & $\operatorname{Max}$ \\
\hline " & 2 & 433 & $\mathrm{~N}$ & $" n$ & n \\
\hline$n$ & 3 & 431 & $\mathrm{~N}$ & $"$ & " \\
\hline " & 4 & 429 & $\mathrm{~N}$ & " & n \\
\hline " & 5 & 438 & $\mathrm{~N}$ & $"$ & n \\
\hline$n$ & 6 & 434 & $\mathrm{~N}$ & $"$ & " \\
\hline
\end{tabular}


Table 3. Test results, group C samples.

\begin{tabular}{|c|c|c|c|c|c|}
\hline $\begin{array}{l}\text { Vest } \\
\text { I.D. }\end{array}$ & $\begin{array}{c}\text { Shot } \\
\text { Location }\end{array}$ & $\begin{array}{c}\text { Impact } \\
\text { Velocity }(\mathrm{m} / \mathrm{s})\end{array}$ & Penetration & Size & $\begin{array}{l}\text { Shot } \\
\text { Pattern }\end{array}$ \\
\hline $3 F$ & 1 & 439 & $\mathrm{~N}$ & $46 / 48 \mathrm{R}$ & Min \\
\hline$n$ & 2 & 435 & $\mathbf{N}$ & $n$ & $"$ \\
\hline " & 3 & 432 & $\mathrm{~N}$ & $n$ & $"$ \\
\hline$n$ & 4 & 439 & $\mathbf{N}$ & $"$ & $n$ \\
\hline$n$ & 5 & 429 & $\mathrm{Y}$ & $n$ & $n$ \\
\hline$"$ & 6 & 434 & $\mathbf{N}$ & $"$ & $"$ \\
\hline $6 \mathrm{~F}$ & 1 & 435 & $\mathbf{N}$ & $50 / 52 \mathrm{~L}$ & Min \\
\hline$n$ & 2 & 436 & $\mathbf{N}$ & n & $"$ \\
\hline$n$ & 3 & 430 & $\mathrm{~N}$ & $"$ & $n$ \\
\hline$n$ & 4 & 431 & $\mathrm{~N}$ & $n$ & $n$ \\
\hline$n$ & 5 & 430 & $\mathrm{~N}$ & $n$ & $n$ \\
\hline$n$ & 6 & 435 & $\mathbf{N}$ & $"$ & $n$ \\
\hline $11 \mathrm{~F}$ & 1 & 435 & $\mathbf{N}$ & $46 / 48 \mathrm{~L}$ & Min \\
\hline$n$ & 2 & 439 & $\mathrm{~N}$ & n & \\
\hline$"$ & 3 & 435 & $\mathrm{~N}$ & $n$ & $"$ \\
\hline$n$ & 4 & 432 & $\mathrm{~N}$ & $n$ & $"$ \\
\hline$"$ & 5 & 429 & $\mathrm{~N}$ & $n$ & $"$ \\
\hline$"$ & 6 & 435 & $\mathbf{N}$ & $n$ & $"$ \\
\hline $14 \mathrm{~F}$ & 1 & 434 & $\mathrm{~N}$ & $46 / 48 S$ & Min \\
\hline$"$ & 2 & 429 & $\mathbf{N}$ & " & $"$ \\
\hline$"$ & 3 & 439 & $\mathrm{~N}$ & $n$ & $"$ \\
\hline$"$ & 4 & 431 & $\mathbf{N}$ & $"$ & $"$ \\
\hline$"$ & 5 & 436 & $\mathbf{N}$ & $n$ & $"$ \\
\hline$n$ & 6 & 433 & $\mathrm{~N}$ & $n$ & $"$ \\
\hline $3 \mathrm{~B}$ & 1 & 430 & $\mathrm{~N}$ & $46 / 48 \mathrm{R}$ & Min \\
\hline$"$ & 2 & 430 & $\mathrm{~N}$ & " & $"$ \\
\hline$"$ & 3 & 437 & $\mathrm{Y}$ & $"$ & $"$ \\
\hline$n$ & 4 & 430 & $\mathrm{~N}$ & $n$ & $n$ \\
\hline$n$ & 5 & 433 & $\mathrm{~N}$ & $"$ & $n$ \\
\hline$n$ & 6 & 430 & $\mathbf{N}$ & $n$ & $n$ \\
\hline $6 \mathrm{~B}$ & 1 & 430 & $\mathbf{N}$ & $50 / 52 \mathrm{~L}$ & Min \\
\hline$n$ & 2 & 429 & $\mathrm{~N}$ & n & " \\
\hline$"$ & 3 & 432 & $\mathbf{N}$ & $n$ & $"$ \\
\hline$n$ & 4 & 433 & $\mathrm{~N}$ & $n$ & $n$ \\
\hline$n$ & 5 & 433 & $\mathrm{~N}$ & $n$ & $n$ \\
\hline$n$ & 6 & 438 & $\mathrm{~N}$ & $n$ & $n$ \\
\hline $11 B$ & 1 & 431 & $\mathrm{~N}$ & $46 / 48 \mathrm{~L}$ & Min \\
\hline$n$ & 2 & 436 & $\mathbf{N}$ & n & $n$ \\
\hline$n$ & 3 & 431 & $\mathbf{N}$ & $n$ & $n$ \\
\hline$n$ & 4 & 430 & $\mathrm{~N}$ & $n$ & $n$ \\
\hline$"$ & 5 & 429 & $\mathbf{N}$ & " & $n$ \\
\hline$"$ & 6 & 431 & $\mathrm{Y}$ & $"$ & $n$ \\
\hline $14 \mathrm{~B}$ & 1 & 433 & $\mathrm{~N}$ & $46 / 48 S$ & Min \\
\hline$"$ & 2 & 430 & $\mathbf{N}$ & 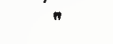 & $n$ \\
\hline$"$ & 3 & 432 & $\mathrm{~N}$ & $"$ & $n$ \\
\hline$n$ & 4 & 430 & $\mathrm{~N}$ & " & $n$ \\
\hline$n$ & 5 & 434 & $\mathbf{N}$ & $"$ & $n$ \\
\hline$n$ & 6 & 426 & $\mathbf{N}$ & $n$ & $n$ \\
\hline
\end{tabular}


Table 4. Test results, group D samples.

\begin{tabular}{|c|c|c|c|c|c|}
\hline $\begin{array}{l}\text { Vest } \\
\text { I.D. }\end{array}$ & $\begin{array}{c}\text { Shot } \\
\text { Location }\end{array}$ & $\begin{array}{c}\text { Impact } \\
\text { Velocity }(\mathrm{m} / \mathrm{s})\end{array}$ & Penetration & Size & $\begin{array}{c}\text { Shot } \\
\text { Pattern }\end{array}$ \\
\hline $4 \mathrm{~F}$ & 1 & 433 & $\mathbf{N}$ & $38 / 40 \mathrm{~S}$ & Min \\
\hline$n$ & 2 & 434 & $\mathbf{N}$ & $n$ & $n$ \\
\hline$"$ & 3 & 429 & $\mathbf{N}$ & $n$ & $n$ \\
\hline$n$ & 4 & 429 & $\mathbf{N}$ & $n$ & " \\
\hline$"$ & 5 & 437 & $\mathbf{N}$ & $n$ & $"$ \\
\hline$n$ & 6 & 437 & $\mathbf{N}$ & $n$ & $"$ \\
\hline $5 F$ & 1 & 438 & $\mathbf{N}$ & $38 / 40 \mathrm{R}$ & Min \\
\hline$n$ & 2 & 436 & $\mathbf{N}$ & $n$ & $n$ \\
\hline$"$ & 3 & 432 & $\mathbf{N}$ & $n$ & $n$ \\
\hline$n$ & 4 & 426 & $\mathbf{N}$ & $n$ & $n$ \\
\hline$n$ & 5 & 430 & $\mathrm{Y}$ & $n$ & $n$ \\
\hline$"$ & 6 & 433 & $\mathrm{~N}$ & $"$ & $n$ \\
\hline $12 \mathrm{~F}$ & 1 & 440 & $\mathbf{N}$ & $34 / 36 R$ & $\operatorname{Min}$ \\
\hline$n$ & 2 & 432 & $\mathbf{N}$ & " & $n$ \\
\hline$n$ & 3 & 428 & $\mathrm{~N}$ & $n$ & $n$ \\
\hline$n$ & 4 & 430 & $\mathbf{N}$ & $n$ & $n$ \\
\hline$n$ & 5 & 426 & $\mathbf{N}$ & $n$ & $"$ \\
\hline$"$ & 6 & 436 & $\mathbf{N}$ & " & $"$ \\
\hline $13 \mathrm{~F}$ & 1 & 440 & $\mathbf{N}$ & $34 / 36 R$ & Min \\
\hline$n$ & 2 & 435 & $\mathrm{~N}$ & n & $n$ \\
\hline$n$ & 3 & 434 & $\mathbf{N}$ & $n$ & $"$ \\
\hline$n$ & 4 & 434 & $\mathbf{N}$ & $n$ & $"$ \\
\hline$n$ & 5 & 433 & $\mathbf{N}$ & $"$ & $n$ \\
\hline$n$ & 6 & 429 & $\mathrm{Y}$ & $n$ & $n$ \\
\hline $4 B$ & 1 & 434 & $\mathbf{N}$ & $38 / 40 \mathrm{~S}$ & Min \\
\hline " & 2 & 432 & $\mathbf{N}$ & n & $n$ \\
\hline$n$ & 3 & 430 & $\mathrm{Y}$ & $n$ & $n$ \\
\hline$n$ & 4 & 433 & $\mathbf{N}$ & $n$ & $n$ \\
\hline " & 5 & 430 & $\mathbf{N}$ & $n$ & $"$ \\
\hline$n$ & 6 & 429 & $\mathbf{N}$ & $n$ & $"$ \\
\hline $5 B$ & 1 & 430 & $\mathbf{N}$ & $34 / 36 \mathrm{R}$ & Min \\
\hline$n$ & 2 & 435 & $\mathbf{N}$ & " & " \\
\hline$n$ & 3 & 429 & $\mathbf{N}$ & $n$ & $"$ \\
\hline$n$ & 4 & 434 & $\mathbf{N}$ & $n$ & $"$ \\
\hline$n$ & 5 & 427 & $\mathbf{N}$ & $"$ & $n$ \\
\hline$n$ & 6 & 429 & $\mathbf{N}$ & $"$ & $"$ \\
\hline $12 \mathrm{~B}$ & 1 & 432 & $\mathbf{N}$ & $34 / 36 \mathrm{R}$ & Min \\
\hline$"$ & 2 & 436 & $\mathbf{N}$ & " & $n$ \\
\hline$n$ & 3 & 431 & $\mathbf{N}$ & $"$ & $n$ \\
\hline$n$ & 4 & 433 & $\mathrm{~N}$ & $n$ & $n$ \\
\hline$n$ & 5 & 434 & $\mathbf{N}$ & $n$ & $n$ \\
\hline$"$ & 6 & 436 & $\mathbf{N}$ & $n$ & $n$ \\
\hline $13 B$ & 1 & 434 & $\mathbf{N}$ & $34 / 36 \mathrm{R}$ & Min \\
\hline$n$ & 2 & 431 & $\mathbf{N}$ & n & $n$ \\
\hline " & 3 & 434 & $\mathbf{N}$ & $n$ & $n$ \\
\hline$n$ & 4 & 431 & $\mathbf{N}$ & $"$ & $n$ \\
\hline$"$ & 5 & 435 & $\mathbf{N}$ & $n$ & $n$ \\
\hline$"$ & 6 & 432 & $\mathbf{N}$ & $n$ & $n$ \\
\hline
\end{tabular}


Group A Group B Group C Group D

$\begin{array}{lclll}\text { Front } & 5,6 & 0 & 5 & 0 \\ \text { Panels } & 0 & 0 & 0 & 5 \\ & 0 & 0 & 0 & 0 \\ & 3,6 & 0 & 0 & 6\end{array}$

$\begin{array}{lccll}\text { Back } & 6 & 0 & 3 & 3 \\ \text { Panels } & 0 & 0 & 0 & 0 \\ & 2,6 & 6 & 6 & 0 \\ & 0 & 0 & 0 & 0\end{array}$

Figure 6. Penetration distribution for the four test groups;

0 indicates no penetrations, numbers identify the impact locations of penetrations.

\section{ANALYSIS OF DATA}

The limited test described in this report was designed to allow estimation of, and testing for the possible existence of, effects on test results due to nominal vest size and/or shot pattern size. The limitation on the number of tests that could be run implies that a large effect had a moderate chance of being detected (i.e., showing a statistically significant difference) while a small, but real, effect could easily escape detection.

In the data obtained from this experiment, none of the factors investigated (vest size nor shot pattern size nor front-versus-back) showed a statistically significant effect. The immediate practical interpretation of this result is that the true effects, if any, are unlikely to be very "large." It is then of interest to determine what magnitude defines the "large" effects that can now be essentially ruled-out on the basis of the experimental results obtained.

\section{Global Data Analysis}

Table 5 shows a summary of the 192 shot impacts that were analyzed in this study. The final column is consistent with the experience of other studies in that the penetration rate varies with the impact location (shot number) in the NIJ-03 sequence. A proper statistical analysis of the data at the per-shot level would require creation and interpretation of a detailed mathematical model that accounts for these differences. In the following, a simpler approach is used by analyzing the data on a per-panel basis. 
Table 5. Summary of tests for effect of vest size on penetration rate.

\begin{tabular}{|c|c|c|c|c|c|c|c|c|c|c|c|c|c|}
\hline \multirow{3}{*}{$\begin{array}{c}\text { Shot } \\
\text { location }\end{array}$} & \multicolumn{12}{|c|}{ Nominal vest size (shot pattern) } & \multirow{3}{*}{$\begin{array}{l}\text { Total } \\
\text { number } \\
\text { of } \\
\text { Pen's }\end{array}$} \\
\hline & \multicolumn{2}{|c|}{$34 / 36(\mathrm{Min})$} & \multicolumn{2}{|c|}{$38 / 40(\mathrm{Min})$} & \multicolumn{2}{|c|}{$42 / 44$ (Max) } & \multicolumn{2}{|c|}{ 42/44 (Min) } & \multicolumn{2}{|c|}{ 46/48 (Min) } & \multicolumn{2}{|c|}{$50 / 52$ (Min) } & \\
\hline & Stops & Pen's & Stops & Pen's & Stops & Pen's & Stops & Pen's & Stops & Pen's & Stops & Pen's & \\
\hline 1 & 5 & 8 & 3 & 0 & 8 & 0 & 8 & 0 & 6 & 8 & 2 & 0 & 0 \\
\hline 2 & 5 & 8 & 3 & 0 & 8 & 6 & 7 & 6 & 6 & 8 & 2 & 0 & 1 \\
\hline 3 & 5 & $\underline{1}$ & 2 & 1 & 2 & $\underline{1}$ & 7 & 1 & 1 & 1 & 1 & 0 & 3 \\
\hline 4 & 5 & 0 & 3 & 0 & 8 & 0 & 8 & 0 & 6 & 8 & 2 & 0 & 0 \\
\hline 5 & 5 & 0 & 2 & 1 & 8 & 0 & 7 & 1 & 5 & 1 & 2 & 0 & 3 \\
\hline 6 & 4 & 1 & 3 & 0 & 7 & 1 & 4 & 4 & 5 & 1 & 2 & 0 & 7 \\
\hline Totals & 29 & 1 & 16 & 2 & 47 & 1 & 41 & 7 & 33 & 3 & 12 & 0 & 14 \\
\hline
\end{tabular}

Table 6 summarizes the data in terms of the results for the 32 vest panels that were tested in this study. Inspection of the table shows that 5 of the 16 front panels were penetrated and 6 of the 16 back panels were penetrated. The informal conclusion from this observation is that there is apparently no difference between the long-run penetration rates for front and back panels, at least for this vest model. However, since there were only 16 front and back panels tested, these results are also consistent with the existence of a real difference of some magnitude between the long-run penetration rates of front and back panels. To quantify these possibilities requires analysis of the data by a statistical model.

Table 6. Data summary on per-panel basis.

\begin{tabular}{|c|c|c|c|c|c|c|c|c|}
\hline & & \multicolumn{6}{|c|}{ Nominal Vest Size (Shot Pattern Size) } & \multirow[b]{2}{*}{ Totals } \\
\hline & & $\begin{array}{l}34 / 36 \\
\text { (Min) }\end{array}$ & $\begin{array}{l}38 / 40 \\
(\mathrm{Min})\end{array}$ & $\begin{array}{l}42 / 44 \\
(\operatorname{Max})\end{array}$ & $\begin{array}{l}42 / 44 \\
(\mathrm{Min})\end{array}$ & $\begin{array}{l}46 / 48 \\
\text { (Min) }\end{array}$ & $\begin{array}{l}50 / 52 \\
(\mathrm{Min})\end{array}$ & \\
\hline \multirow{2}{*}{$\begin{array}{l}\text { Panels } \\
\text { Penetrated }\end{array}$} & Front & 1 & 1 & 0 & 2 & 1 & 0 & 5 \\
\hline & Back & 0 & 1 & - & 2 & 2 & 2 & 6 \\
\hline \multirow{2}{*}{$\begin{array}{l}\text { Panels Not } \\
\text { Penetrated }\end{array}$} & Front & - & 1 & 1 & 2 & 2 & 1 & 10 \\
\hline & Back & - & 2 & - & 2 & 1 & 1 & 10 \\
\hline \multicolumn{2}{|c|}{ Total Penetrated } & 1 & 2 & 1 & 4 & 3 & 0 & 11 \\
\hline \multicolumn{2}{|c|}{ Total Not Penetrated } & 4 & 1 & 7 & 4 & 3 & 2 & 21 \\
\hline
\end{tabular}


The data were analyzed using a logistic regression model in which the logarithm of the odds ratio in favor of no penetration was modeled as a linear function of three variables: vest size ( 5 levels), shot pattern size ( 2 levels), and front-versus-back ( 2 levels). The parameters of this model were estimated by the method of maximum likelihood, with the results shown in table 7 . None of the three variables showed a statistically significant effect - i.e., all of the estimated parameter values were not significantly different from zero (at the 0.05 level). Of the three, the variable coming nearest to significance was the shot pattern size $(p=0.16)$. Effects are usually considered not statistically significant unless the calculated significance probability " $\mathrm{p}$ " is less than 0.05 . Increasingly strong evidence of a real effect is indicated by a smaller significance probability, or p-value.

This lack of attained statistical significance in this experiment is due partly to the fact that, like the informal front-versus-back analysis reviewed above, the penetration results were not much different across the conditions tested. Another reason is that the number of panels tested was fairly limited. In general, subtle effects can be detected (i.e., yield statistically significant parameter estimates) only if the number of tests is large.

Table 7. Analysis of maximum likelihood estimates.

\begin{tabular}{|c|c|c|c|}
\hline Parameter & Estimate & Standard error & Significance probability, $\mathrm{p}$ \\
\hline Constant Term & 1.484 & 3.558 & 0.68 \\
\hline Shot Pattern Size & 0.810 & 0.575 & 0.16 \\
\hline Nominal Vest Size & -0.008 & 0.084 & 0.92 \\
\hline Front-vs-Back & -0.151 & 0.388 & 0.70 \\
\hline
\end{tabular}

\section{Detailed Analysis of Shot Pattern Size}

We now take up the question of quantifying the range of possible effects due to shot pattern size, based on the evidence in this limited experiment. This question is answered from the data in table 7 by constructing an approximate $95 \%$ confidence interval for the possible size of the statistical parameter representing the effect of shot pattern size. Taking \pm 2 standard errors (" \pm 2 -sigma") as the statistical uncertainty in the estimated logistic regression parameter value yields the interval $0.81 \pm 1.15$, which extends from -0.34 to 1.96 . Although it is hard to interpret the magnitude of these numbers (which are in log-odds scale) it is at least clear that the sign of the parameter estimate is indeterminate. That is, the data do not clearly indicate whether changing from the minimum to the maximum shot pattern increases, or decreases, the probability of no penetrations on the panel. This is another way to say that the effect of shot pattern size is not significantly different from zero. 
To put these results on a more easily-interpreted scale, they can be transformed to give the probability that a vest model would pass a full NIJ-03 test sequence. For the purpose of the following calculations, it is assumed that there would be no systematic difference in penetration results due to either the wet condition testing, or due to the second type of ammunition used in the NIJ-03 test.

For convenience, we arbitrarily choose to normalize the calculations using the results for maximum pattern as the base case. In the experimental data for the maximum pattern, one panel out of eight (12.5\%) was penetrated. From the logistical model, the corresponding estimate for the minimum pattern is $41.9 \%$. If a vest model having long-run probability of penetration per panel equal to $12.5 \%$ were tested to the NIJ-03 standard, then the probability of failing the full 03 test would be $1-(1-.125)^{8}=0.656$, or $65.6 \%$. (The exponent 8 in the equation reflects the fact that four complete vests, or eight panels, would be tested under NIJ-03.)

By comparison, the probability of failing the NIJ-03 test using the minimum spacing condition, as estimated by the maximum likelihood (ML) estimate would be $98.7 \%$. Allowing for the uncertainty in the ML estimate yields a $95 \%$ confidence interval of $42.9 \%$ to $100 \%$. Loosely speaking, for a vest model having a $65.6 \%$ chance of failing the NIJ-03 test sequence using the maximum shot pattern spacing, changing to the minimum shot pattern is estimated to increase the chance of failing to $98.7 \%$, with confidence interval extending from $42.9 \%$ to essentially $100 \%$. Note that, at the lower end of this confidence interval, the data are consistent with the possibility that the effect of changing to the minimum shot pattern could actually reduce the chance of failing the NIJ-03 test from $65.6 \%$ to $42.9 \%$. This again reflects the degree of indeterminacy in the results of this limited experiment.

\section{Effect of Nominal Vest Size}

In parallel with the analogy with the calculations described for shot pattern size, similar calculations can be made for the effects of nominal vest size. We again normalize the calculations to apply to a vest model having a $65.6 \%$ chance of failing NIJ-03. This base case will be taken to be a vest of nominal size 50/52, and the comparison will be with a vest of size 34/36. The ML estimate of the probability of failing NIJ-03 in this case drops slightly to $61.2 \%$ for size $34 / 36$ vests. Taking into account the statistical uncertainty (as reflected in the $95 \%$ confidence interval) yields an interval extending from $6.6 \%$ to essentially $100 \%$ chance of failing.

\section{Effect of Front Versus Back Panel}

In table 6 , it is readily observed that the proportion of panels penetrated was just slightly higher for back panels $(6 / 16)$ than for front panels $(5 / 16)$. This is reflected in table 7 by the negative ML estimate of the parameter that defines the change in log-odds of nonpenetration when going from front to back panels. To put this comparison on a numerical 
scale similar to the previous examples requires consideration of an (unrealistic) NIJ-03 type test using, in one case, eight front panels, and in the comparison case, eight back panels. To normalize the calculations, we take (arbitrarily) the base case to be an eight-panel test exclusively using back panels. If the back panels had a probability of (at least one) penetration of 0.125 , the probability of failing the NIJ-03 (8-panel) test would be $65.6 \%$, as before. If a similar test were run exclusively on front panels, the ML estimated probability of failing the NIJ-03 (8-panel) test would be $55.2 \%$, with a $95 \%$ confidence interval extending from 16.2 to $96.1 \%$. In accord with the simple data summary in table 6 , the ML estimate of the chance of failing the test drops slightly in going from back to front panels, but the uncertainty is large enough that the $95 \%$ confidence interval covers a range that includes both lower and higher probabilities.

\section{Summary for Three Parameters}

For comparison, the calculated confidence intervals corresponding to the three parameters discussed above are summarized in table 8.

Table 8. Confidence intervals, corresponding to three test parameters, for estimated change in probability of failing an NIJ-03 test.

\begin{tabular}{|c|c|c|c|c|c|}
\hline \multicolumn{2}{|c|}{$\begin{array}{l}\text { Base Case: } \\
\text { Penetration Probability } \\
\text { for a Single Panel } \\
\text { Assumed to be } 0.125\end{array}$} & \multicolumn{4}{|c|}{$\begin{array}{c}\text { Comparison Case: } \\
\text { Penetration Probability for a Single Panel } \\
\text { Estimated From Data }\end{array}$} \\
\hline \multirow[b]{2}{*}{ Description } & \multirow{2}{*}{$\begin{array}{l}\text { Calculated } \\
\text { Probability of } \\
\text { Failing an } \\
\text { NIJ-03 Test }\end{array}$} & \multirow[b]{2}{*}{ Description } & \multicolumn{3}{|c|}{ Probability of Failing an NIJ-03 Test } \\
\hline & & & $\begin{array}{l}\text { Lower } 95 \% \\
\text { Confidence } \\
\text { Limit }\end{array}$ & $\begin{array}{l}\text { Maximum } \\
\text { Likelihood } \\
\text { Estimate }\end{array}$ & $\begin{array}{l}\text { Upper } 95 \% \\
\text { Confidence } \\
\text { Limit }\end{array}$ \\
\hline Max. Pattern & 0.656 & Min. Pattern & 0.429 & 0.987 & 1.000 \\
\hline Size $50 / 52$ & 0.656 & Size $34 / 36$ & 0.066 & 0.612 & 1.000 \\
\hline Back Panels & 0.656 & Front Panels & 0.162 & 0.552 & 0.961 \\
\hline
\end{tabular}

\section{Possible Reduction of Statistical Uncertainty by Increasing Experiment Size}

The 95\% confidence intervals shown in table 8 are of limited usefulness because they are so wide. This excessive width could be reduced by running a larger experiment. To gain an understanding of the effect of increasing the experiment size, the calculations for table 8 can be repeated (in tables 9 and 10) assuming that the number of panels tested had been 
Table 9. Illustration of confidence interval widths obtainable by increasing number of test panels, for case of shot pattern size (maximum vs. minimum spacing condition).

\begin{tabular}{|c|c|c|c|c|c|c|}
\hline \multicolumn{2}{|c|}{$\begin{array}{c}\text { Assumed } \\
\text { Experiment Size }\end{array}$} & \multicolumn{5}{|c|}{ Calculated Probability of Failing Full NIJ-03 Test Sequence } \\
\hline \multirow[b]{2}{*}{ "N" } & \multirow{2}{*}{$\begin{array}{c}\text { Number } \\
\text { of Test } \\
\text { Panels }\end{array}$} & \multirow{2}{*}{$\begin{array}{c}\text { Assumed } \\
\text { Base Case } \\
\text { (Maximum } \\
\text { Spacing) }\end{array}$} & \multicolumn{4}{|c|}{ Comparison Case: Minimum Spacing Condition } \\
\hline & & & $\begin{array}{c}\text { Lower } 95 \% \\
\text { Confidence } \\
\text { Limit }\end{array}$ & $\begin{array}{c}\text { Maximum } \\
\text { Likelihood } \\
\text { Estimate }\end{array}$ & $\begin{array}{c}\text { Upper } 95 \% \\
\text { Confidence } \\
\text { Limit }\end{array}$ & $\begin{array}{l}\text { Width of } \\
\text { Confidence } \\
\text { Interval }\end{array}$ \\
\hline 1 & 32 & 0.656 & 0.429 & 0.987 & 1.000 & 0.571 \\
\hline 2 & 64 & 0.656 & 0.655 & 0.987 & 1.000 & 0.345 \\
\hline 3 & 96 & 0.656 & 0.950 & 0.987 & 1.000 & 0.246 \\
\hline 5 & 160 & 0.656 & 0.841 & 0.987 & 1.000 & 0.159 \\
\hline 10 & 320 & 0.656 & 0.909 & 0.987 & 0.999 & 0.091 \\
\hline 25 & 800 & 0.656 & 0.950 & 0.987 & 0.998 & 0.047 \\
\hline 50 & 1600 & 0.656 & 0.965 & 0.987 & 0.996 & 0.031 \\
\hline 100 & 3200 & 0.656 & 0.973 & 0.987 & 0.994 & 0.021 \\
\hline
\end{tabular}

Table 10. Illustration of confidence interval widths obtainable by increasing number of test panels, for case of nominal vest size (size 50/52 versus size 34/36).

\begin{tabular}{||c|c|c|c|c|c|c||}
\hline \multicolumn{2}{||c|}{$\begin{array}{c}\text { Assumed } \\
\text { Experiment Size }\end{array}$} & \multicolumn{5}{|c|}{ Calculated Probability of Failing Full NIJ-03 Test Sequence } \\
\hline \multirow{2}{*}{ "N" } & $\begin{array}{c}\text { Number } \\
\text { of Test } \\
\text { Panels }\end{array}$ & $\begin{array}{c}\text { Assumed } \\
\text { Base Case } \\
\text { (Size 50/52) }\end{array}$ & $\begin{array}{c}\text { Cower 95\% } \\
\text { Confidence } \\
\text { Limit }\end{array}$ & $\begin{array}{c}\text { Maximum } \\
\text { Likelihood } \\
\text { Estimate }\end{array}$ & $\begin{array}{c}\text { Comparison Case: Nominal Size 34/36 Vests } \\
\text { Confidence } \\
\text { Limit }\end{array}$ & $\begin{array}{c}\text { Confidence } \\
\text { Interval }\end{array}$ \\
\hline 1 & 32 & 0.656 & 0.066 & 0.612 & 1.000 & 0.934 \\
\hline 5 & 160 & 0.656 & 0.256 & 0.612 & 0.939 & 0.683 \\
\hline 10 & 320 & 0.656 & 0.341 & 0.612 & 0.873 & 0.531 \\
\hline 50 & 1600 & 0.656 & 0.482 & 0.612 & 0.740 & 0.258 \\
\hline 100 & 3200 & 0.656 & 0.519 & 0.612 & 0.704 & 0.184 \\
\hline 500 & 16000 & 0.656 & 0.570 & 0.612 & 0.653 & 0.083 \\
\hline
\end{tabular}


a factor "N" times as large as it was, that is, as if the number of panels had been 5 or 10 times 32 ( 160 or 320 ) instead of 32 . (Tables 9 and 10 , following, were constructed from the estimates shown in table 7 by dividing the standard errors by $\sqrt{\mathrm{N}}$.) The resulting tables give estimates of how much one could expect the widths of the confidence intervals to be reduced with increasing experiment size. Estimates for the effects of shot pattern spacing are given in table 9 and for nominal vest size in table 10.

Notice that the calculation shown in table 10 implies that, on the basis of the data obtained, it is estimated that about 16,000 test panels would have to be shot with the NIJ-03 sequence in order to obtain statistically significant evidence of a real effect due to nominal vest size. [Statistical significance would be established for $\mathrm{N}=500$ because the assumed base case probability of failing the NIJ-03 test $(-65.6 \%)$ lies outside the confidence interval computed for the comparison case $(57.0 \%$ to $65.3 \%)$.] The reader should keep in mind that this calculation assumes that the magnitude of the estimated effect due to nominal vest size, i.e., the maximum likelihood estimate shown in table 7, would be unchanged in the larger experiment, while the standard error would be reduced by the factor $1 / \sqrt{\mathrm{N}}$.

It is also interesting to note that, in the data obtained, the direction of the estimated effect for nominal vest size is counter-intuitive. The estimate obtained implies that smaller vests (size 34/36) would be more likely to pass the full NIJ-03 test sequence than larger ones (size 50/52), but as has been emphasized above, this estimated trend is not statistically significant.

In reviewing the analysis discussed above, it is worth noting that the statistical reliability of the NIJ-03 test procedure cannot be inferred from the widths of the confidence intervals in tables 8-10. The statistical problem treated in those tables is different from (and more demanding than) an assessment of NIJ-03 because it involves comparisons of test results across several experimental conditions (five vest sizes, two shot patterns, and front versus back panels). Since eight panels are required to run one complete NIJ-03 test, the data analyzed for the 32 panels in this experiment amount to running only four complete NIJ-03 tests.

Further, since the armor under test is of marginal ballistic resistance (the probability of passing NIJ-03 is close to 0.5 in the "base case" conditions studied), statistical uncertainty in the penetration probability for an individual panel is greatly amplified when converted to predictions about the probability of passing the full NIJ-03 test.

\section{CONCLUSIONS AND RECOMMENDATIONS}

None of the factors investigated in this study (sample size, shot pattern, and front-versusback) showed a statistically significant effect. However, the confidence intervals obtained by analysis of the data from this limited study are wide, and it is not possible to state that subtle, or even somewhat pronounced, effects do not exist. 
Considering nominal vest size, the present data suggest a subtle trend implying that smaller size armor would be slightly more likely to pass the full NIJ Standard-0101.03 test than larger size armor, assuming that the shot pattern size remains constant. Since the estimated trend is small, particularly in comparison to its statistical uncertainty, it may be simply a manifestation of the random variation in the test results. It is estimated that an experiment involving tests of about 8000 sets of armor (16,000 front and back panels) would be required to obtain statistically significant evidence that would establish whether such a subtle trend is real. Both the magnitude of the experiment required to quantify this effect, and the direction of the estimated trend, support the conclusion that the size of the armor, alone, is not critical to the results obtained when armor is tested in accordance with NIJ Standard-0101.03.

It is also estimated that about 400 sets of armor ( 800 panels) would have to be tested in order to obtain acceptable statistical precision in the estimate of the possible effect due to shot pattern size. That is, by testing 800 panels, the width of the confidence interval shown in table 9 would be reduced to about 0.05 . The cost of such an experiment could exceed $\$ 300,000$.

We believe that the expense of the experiments discussed above is not warranted because the possible effects of sample size and shot pattern size can be avoided by not testing small size armor, which in turn permits the use of a larger shot pattern.

We therefore recommend that any testing under the control of the NIJ body armor compliance testing program use test specimens no smaller than that sized to fit a $1.17 / 1.22$ $\mathrm{m}(46 / 48 \mathrm{in})$ chest for male armor, and no smaller than a $91 / 97 \mathrm{~cm}(36 / 38 \mathrm{in})$ chest for female armor.

In addition, we recommend that NIJ notify body armor manufacturers of the results of this study, and advise law enforcement agencies against submitting small size armor for either acceptance testing or service-life testing to be conducted in accordance with NIJ Standard-0101.03. In so doing, NIJ should state that it is unlikely that either the size of the armor or the size of the impact location pattern will have a major effect upon the test results, however, since the possibility does exist, it may not be fair to the manufacturers to conduct tests on small size armor. 


\section{APPENDIX A - Impact Location Spacing}

Upon completion of the testing program, the distances between impact points for the numbers 4,5 , and 6 test sequence were measured. The distances, from the outside edges of the bullet impact locations are presented in tables A-1 and A-2. As shown in figure A-1, $\mathrm{A}$ is the distance between impacts numbers 4 and $5, \mathrm{~B}$ is the distance between impacts numbers 4 and 6 , and $C$ is the distance between impacts 5 and 6 .

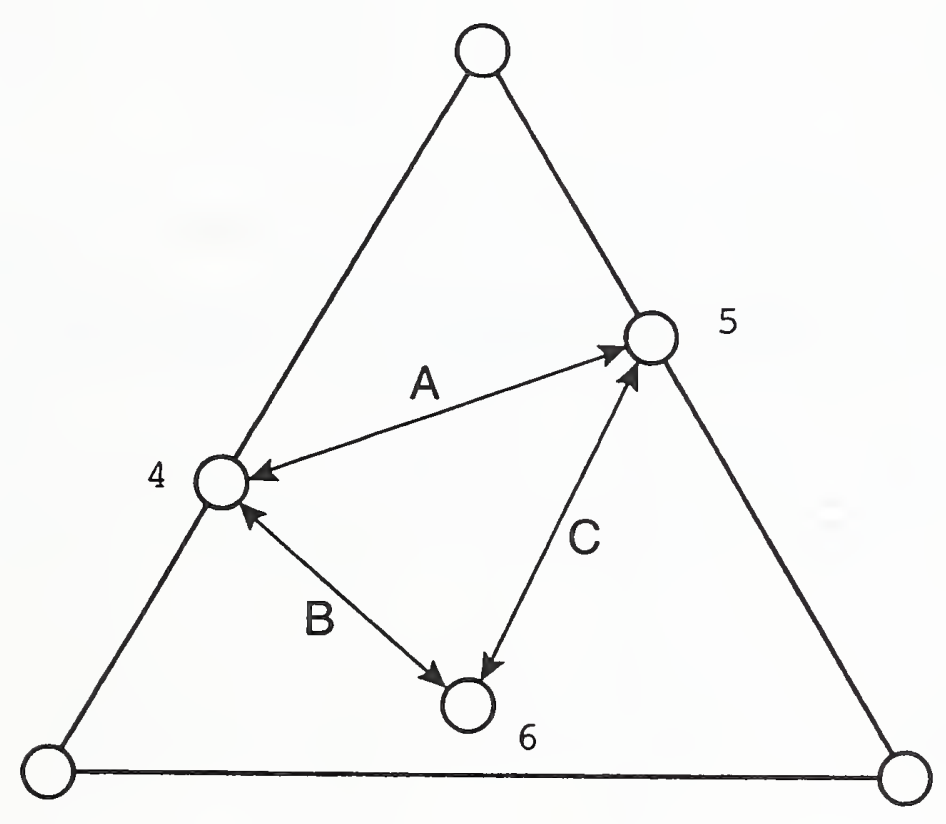

Figure A-1. Impact location spacing dimensions. 
Table A-1. Front panel impact location spacing (cm).

(See fig. A-1)

$\begin{array}{lrrr}\text { Sample } & \text { A } & \text { B } & \text { C } \\ \text { 1F } & & & \\ \text { 2F } & 5.4 & 7.6 & 7.0 \\ \text { 3F } & 15.2 & 7.6 & 8.9 \\ 4 \mathrm{~F} & 4.8 & 12.7 & 9.8 \\ \text { 5F } & 6.7 & 7.9 & 10.8 \\ 6 \mathrm{~F} & 6.0 & 5.1 & 7.3 \\ \text { 7F } & 6.4 & 6.4 & 8.6 \\ 8 \mathrm{~F} & 13.3 & 6.7 & 9.5 \\ \text { 9F } & 7.0 & 8.9 & 8.9 \\ \text { 10F } & 7.3 & 8.3 & 8.3 \\ \text { 11F } & 14.3 & 10.5 & 9.5 \\ \text { 12F } & 6.7 & 6.4 & 7.6 \\ \text { 13F } & 3.2 & 9.2 & 8.9 \\ \text { 14F } & 7.0 & 7.0 & 8.6 \\ \text { 15F } & 6.4 & 9.5 & 8.9 \\ \text { 16F } & 15.9 & 11.7 & 14.3 \\ & 7.3 & 8.3 & 8.6\end{array}$

Table A-2. Back panel impact location spacing (cm). (See fig. A-1)

$\begin{array}{lrrr}\text { Sample } & \text { A } & \text { B } & \text { C } \\ \text { 1B-A } & & & \\ \text { 2B } & 4.8 & 7.6 & 8.6 \\ \text { 3B } & 14.6 & 11.7 & 13.6 \\ \text { 4B } & 7.0 & 10.5 & 10.5 \\ \text { 5B } & 7.3 & 7.3 & 8.9 \\ \text { 6B } & 6.7 & 8.3 & 5.1 \\ \text { 7B } & 5.7 & 6.4 & 5.7 \\ \text { 8B } & 14.0 & 8.6 & 10.8 \\ \text { 9B } & 7.0 & 8.3 & 6.7 \\ \text { 10B } & 7.0 & 7.3 & 8.3 \\ \text { 11B } & 14.6 & 10.2 & 8.9 \\ \text { 12B } & 5.1 & 6.7 & 7.0 \\ \text { 13B } & 6.4 & 4.4 & 6.4 \\ \text { 14B } & 5.7 & 7.9 & 8.3 \\ \text { 15B } & 7.0 & 6.7 & 7.9 \\ \text { 16B } & 15.6 & 10.5 & 7.4 \\ & 6.7 & 4.8 & \end{array}$


NIST-114A

(REV. 3-90)
BIBLIOGRAPHIC DATA SHEET

\section{U.S. DEPARTMENT OF COMMERCE \\ NATIONAL INSTITUTE OF STANDARDS AND TECHNOLOGY}

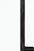

3. PUBLCATION DATE

October 1992

4. TITLEAND SUBTITLE

Limited Tests to Investigate Whether the Size of Body Armor Samples Influences Ballistic Test Results

5. AUTHOR(S)

Keith R. Eberhardt and Lawrence K. Eliason

6. PERFORMING ORGANIZATION (IF JOINT OA OTHER THAN NIST, SEE INSTRUCTIONS)

\section{U.S. DEPARTMENT OF COMMERCE}

MATIONAL INSTITUTE OF STANDARDS AND TECHNOLOGY

GAITHERSBURG, MD 20899

\begin{tabular}{l} 
7. CONTAACT/GRANT NUMBER \\
\hline 8. TYPE OF REPORT AND PERIOD COVERED \\
FinOI
\end{tabular}

9. SPONSORING ORGANIZATION MAME AND COMPLETE ADDRESS (STREET, CITY, STATE, ZIP)

National Institute of Justice

633 Indiana Ave., NW.

Washington, DC 20531

10. SUPPLEMENTARY NOTES

11. ABSTAACT (A 200-WOAD OA LESS FACTUAL SUMMARYY OF MOST SIGNIFICANT INFOAMATION. IF DOCUMENT INCLUDES A SIGNIFICANT BIBLIOGRAPMY OA UTERATURE SURVEY, MENTION IT HERE)

A limited series of tests was conducted to investigate whether the size of body armor samples influences ballistic results. An analysis of the results was conducted, and none of the factors evaluated (the size of the sample, the size of the impact pattern, or frontversus-back armor panels) were found to be statistically significant. However, the confidence intervals were large and the possibility exists that these factors could have an effect on test results. The analysis determined that a major experiment would be necessary to quantify effects. It is concluded that the size of test samples, alone, is not critical to the results obtained from tests in accordance with NIJ Standard-0101.03.

It appeared that the size of the shot pattern was more likely to have an effect on the results of ballistic testing, than the other factors that were investigated. The expense of the experiments required to quantify the effects of armor size and shot pattern size was not believed to be warranted, for both can be avoided by not conducting tests on small size armor samples.

12. KEY WORDS (6 TO 12 ENTRIES; ALPHABETICAL ORDER; CAPITALZE ONLY PROPER NAMES; AMD SEPARATE KEY WORDS BY SEMICOLONS) ballistic penetration; ballistic testing; body armor; NIJ Standard-0101.03; penetration probability

13. AVAILABILITY

$\mathrm{X}$ UNLMITED

FOR OFFICLAL DISTRIBUTION. DO NOT RELEASE TO MATIOMAL TECHMICAL INFORMATION SERVICE (NTIS).

ORDER FROM SUPERINTENDENT OF DOCUMENTS, U.S. GOVERMMENT PRINTING OFFICE, WASHINGTON, DC 20402.

ORDER FROM NATIONAL TECMNICAL INFORMATION SERVICE (NTIS), SPRINGFIELD, VA 22161.

14. NUMBER OF PRINTED PAGES

32

15. PRICE

A 03 


